\title{
GRUPOS POLÍTICOS DOMINANTES E POLÍTICAS PÚBLICAS: UM ESTUDO SOBRE O CORPO ADMINISTRATIVO DA COMPANHIA DE SANEAMENTO DO PARANÁ (SANEPAR) ENTRE 2003 E 2014
}

\author{
Marcus Roberto de Oliveira ${ }^{2}$
}

- Enviado em 03/01/2016

- Aprovado em 21/02/2016

O abastecimento de água tratada e própria para consumo, o manejo de águas pluviais, o sistema de esgotamento sanitário, o manejo de resíduos sólidos, a limpeza urbana e o controle de agentes patogênicos formam um conjunto de serviços que tem como objetivo promover a saúde das comunidades envolvidas. Nessa lógica, tais ofícios podem ser compreendidos como procedimentos constituintes de políticas públicas de saúde que versam sobre o saneamento ambiental.

Conforme a Constituição de 1988, as responsabilidades em torno da formulação e da implantação de serviços de saneamento ambiental estão distribuídas entre União, estados e municípios (BARROSO, 2007). E se observarmos as diretrizes nacionais acerca do tema, instituídas pela lei 11445 de 5 de janeiro de $2007^{3}$, é possível sustentar que a formulação e implantação desses ofícios públicos estão fundamentadas como elementos essenciais para o exercício da cidadania. Assim, poderia tal consenso, lavrado juridicamente, fomentar o exercício de poder e sustentar a vigência de determinado status quo ${ }^{4}$ numa determinada região? Nesse raciocínio, nossal proposta de pesquisa reside num estudo sobre o corpo administrativo da Companhia de Saneamento do Paraná (SANEPAR), a empresa responsável pelo saneamento ambiental no estado do Paraná que foi

\footnotetext{
${ }^{1}$ Pesquisa de doutorado em andamento sob a orientação do Professor Doutor Ricardo Costa de Oliveira no Programa de Pós-graduação em Sociologia da UFPR.

2 Graduado em Ciências Sociais e mestre em Sociologia Política, ambos pela UFPR. Endereço eletrônico: mr_olivei@yahoo.com.br

${ }^{3}$ http://www.planalto.gov.br/ccivil_03/_ato2007-2010/2007/lei/111445.htm, acesso em 30 de setembro de 2014.

${ }_{4}$ Os termos poder e status quo dizem respeito a um estabelecimento de grupos políticos tradicionalmente dominantes (FAORO, 2001).
} 
fundada em 1963 e que, nas inúmeras disputas paranaenses (políticas, eleitorais, econômicas, ambientais, etc.), tem presença constante na agenda de qualquer grupo político.

Para ilustrar a referida observação, a cúpula da SANEPAR se reuniu em 2011 e instituiu 30 cargos comissionados, os quais foram alcunhados como "consultores estratégicos", e posteriormente mais 14 foram criados. Na interpretação do Ministério Público do Estado do Paraná (MP-PR), "para que um cargo comissionado em empresa pública exista, é necessário que haja uma lei”. Nessa lógica, em abril de 2014, o MP-PR, aceitando a denúncia oferecida pelo Sindicato dos Engenheiros do Paraná (SENGE-PR), "recomendou que as funções fossem extintas, e que o Estatuto Social da empresa, que permite essa manobra, fosse alterado" ${ }^{5}$.

Mas a recomendação do MP-PR foi ignorada e, consequentemente, descumprida pela SANEPAR. Assim, na presente conjuntura, são 44 funcionários, cujos salários podem chegar à R \$ 22 mil ao mês. E uma significativa quantidade desses cargos comissionados é ocupada por pessoas ligadas ao grupo político do governador Beto Richa; entre elas estão "ex-vereadores, ex-deputados, ex-prefeitos, esposa de secretário de Estado e dirigentes" da sucursal paranaense do Partido da Social Democracia Brasileira (PSDB-PR) ${ }^{6}$. Visto que "a recomendação" do MP-PR não foi cumprida, o órgão "ingressou em setembro (de 2014) com uma ação civil pública contra a companhia" 7 .

As indicações políticas na SANEPAR são corriqueiras na política paranaense. Além de Beto Richa, nos governos Jaime Lerner (1994-2002 pelo antigo Partido da Frente Liberal - PFL) e Roberto Requião (2003-2010 pelo Partido de Movimento Democrático Brasileiro - PMDB) o mesmo expediente também foi utilizado (OLIVEIRA, 2012).

Outro ponto que também figura de maneira muito intensa é a lucratividade da parte privada da SANEPAR. A existência desse setor é prevista no estatuto social da companhia e no ano de 2014, juntamente com "o aumento do lucro dos sócios privados da empresa de água e esgoto", também veio um aumento da "oferta de ações como garantia de obrigações contratuais em Parcerias Público-Privadas" 8.

\footnotetext{
5 http://www.gazetadopovo.com.br/vida-publica/mp-aponta-84-cargos-comissionados-ilegais-na-sanepar-e-na-cohaparc1e5dqpprnuz4qqufn2kgib3t; acesso em 05 de julho de 2015.

6 http://www.esmaelmorais.com.br/2015/04/ministerio-publico-confirma-farra-com-cargos-comissionados-na-sanepar/; acesso em 05 de julho de 2015.

${ }^{7}$ Idem referência da nota 4.

${ }^{8}$ Ibidem.
} 
As situações descritas podem ser compreendidas como exemplos práticos recentes do papel estratégico da SANEPAR na cena política paranaense e da utilização do saneamento ambiental enquanto meio de acumulação de capital social (principalmente, político, eleitoral e econômico) com o objetivo de exercício e permanência de poder.

Nesse sentido, uma estrutura da SANEPAR merece atenção: o seu corpo administrativo. Conforme o estatuto da empresa ${ }^{9}$, tal departamento tem a função de aprovar, deliberar e retificar iniciativas que dizem respeito à sua atuação enquanto empresa mista (público-privada) nas diversas áreas organizacionais (políticas públicas, contratações, mercado de ações, empréstimos, financiamentos, etc.), bem como eleger os diretores da companhia. Desse modo, o corpo administrativo da SANEPAR, composto pelo Conselho de Administração, pela Diretoria Executiva e pelo Conselho Fiscal, do alto dos seus crivos burocráticos, é o setor que avaliza as medidas administrativas da empresa e essas permeiam um universo que envolve interesses políticos contextualmente hegemônicos. Assim propomos um estudo sistemático acerca da atuação, dentro daquilo que prevê o estatuto da SANEPAR, do seu corpo administrativo, enfocando as pessoas que ocuparam essas posições estratégicas na companhia entre 2003 e 2014, período esse em que grupos políticos adversários (o PMDB de Roberto Requião entre 2003 e 2010, e o PSDB de Beto Richa entre 2011 e 2014) estiveram à frente da administração da empresa.

Previamente sustentaremos a hipótese de que as políticas públicas de saneamento ambiental (por expressarem um consenso social no que diz respeito à necessidade das mesmas e por demandarem significativos recursos para suas formulações, implantações e administrações) são importantes fomentadoras de capitais sociais (culturais e econômicos) indispensáveis para o exercício de poder na cena política paranaense em questão. Portanto, a SANEPAR é uma instituição decisiva, em especial, nas iniciativas e nas deliberações do seu corpo administrativo. A empresa será compreendida enquanto uma organização oriunda de um conjunto de processos políticos, nos quais os grupos dominantes da política paranaense exercem o poder num contexto em que o saneamento ambiental está consolidado enquanto fato social (DURKHEIM, 2007) e renovam sistematicamente os capitais sociais necessários para manter seus status quo.

Nosso pretenso estudo será iniciado com um levantamento histórico - institucional sobre a SANEPAR. Tal arrolamento consiste numa sistematização de dados e informações oficiais que em 05 de julho de 2015. 
serão coletadas a partir de documentos disponíveis para consulta no Arquivo Público do Paraná, na Biblioteca Pública do Paraná, na SANEPAR e nos sindicatos profissionais envolvidos na operação da companhia.

A vigência de interesses hegemônicos de grupos políticos, o consenso em torno da necessidade dos serviços de saneamento ambiental e o atributo institucional dos municípios brasileiros como entes federativos são questões fundamentais para o mapeamento sistemático dos grupos políticos dominantes na SANEPAR. Assim, após a sistematização oficial, um detalhamento do modus operandi dos dirigentes que compõem o corpo administrativo da empresa será almejado por meio de procedimentos prosopográficos e antroponômicos.

O termo "prosopografia" pode ser compreendido como "a investigação das características comuns de um grupo de atores na história por meio de um estudo coletivo de suas vidas", e sua finalidade "é dar sentido à ação política, ajudar a explicar a mudança ideológica ou cultural, identificar a realidade social e descrever e analisar com precisão a estrutura da sociedade e o grau e a natureza dos movimentos em seu interior" (STONE, 2011, p. 115-116). Tal método é sugerido devido ao fato de apresentar instrumentos que podem detalhar grupos sociais tanto nas suas composições, quanto nas suas atuações públicas.

A antroponomia está associada à produção de pessoas no âmbito social. Na constante interação que envolve as produções materiais, que podem ser compreendidas como as condições materiais vigentes numa vivência humana, e as produções culturais, definidas enquanto as "aptidões para fazer este ou aquele trabalho, a exercer essa ou aquela atividade" (BERTAUX, 1979, p. 56). Nessa lógica, um procedimento antroponômico alude às participações da família, dos amigos, da escola, da igreja, da ocupação profissional e da própria pessoa. Tal orientação metodológica vai ao encontro das iniciativas prosopográficas, e esse conjugado proporciona que um instrumental complemente o outro quando um grupo político figura como objeto de estudo.

Numa primeira perspectiva, a ênfase da conjugação desses norteadores metodológicos reside nos vínculos familiares, intelectuais, profissionais e partidários. Nesse sentido, as relações de parentesco e as alianças constituídas serão os principais pontos explorados, por meio de consultas aos arquivos públicos disponíveis bem como aos arquivos pessoais que poderão ser identificados ao longo da pesquisa. Nesse panorama, as expectativas de investigação atravessarão gerações e formarão um conjugado de agentes a partir de suas biografias, carreiras e respectivas ocupações no espaço social. Para atendê-las, analisaremos cada pessoa componente do corpo administrativo da SANEPAR, juntamente com seus pais, avós, cônjuges e demais descendentes e formadores das 
redes de relacionamento que fundamentam o exercício e a manutenção de poder, pois as relações familiares são elementos importantes na consolidação dessa composição (Ibidem, p. 66).

Concomitantemente a essa segunda fase da pesquisa empírica, a atuação pública dos grupos dirigentes, a repercussão social de suas respectivas atuações à frente da companhia será sistematicamente minudenciada. Assim, as fontes de imprensa (tanto a grande mídia corporativa, quanto o jornalismo alternativo) serão as principais referências. E juntamente, visto que trataremos de uma história recente, a realização de entrevistas junto aos integrantes do corpo administrativo da SANEPAR figura enquanto um procedimento muito interessante. Porém, independente de suas limitações, devido ao fato do exercício de poder e da manutenção do status quo fundamentar nossa tese, temos a consciência que esse importante instrumento metodológico pode ser inviável em determinadas situações.

E finalizando o panorama descrito até o presente momento, as conclusões preliminares obtidas nas referidas etapas da pesquisa empírica serão analisadas á luz dos conceitos de capital social, campo de poder, hegemonia política e processo político.

\section{REFERÊNCIAS}

ALMEIDA, M. H. T.; CARNEIRO, L. P. (2003). "Liderança local, democracia e políticas públicas no Brasil”. Opinião Pública, mai., vol.9, nº 1, p.124-147.

BARROS, R. T. V. et al. (1995). Saneamento - Manual de saneamento e proteção ambiental para os municípios - vol. 2. Belo Horizonte: Escola de Engenharia da UFMG.

BARROSO, L. R. (2007). "Saneamento básico: competências institucionais da União, estados e municípios". Revista Eletrônica de Direito Administrativo Econômico, ago./set./out., nº11, p.1-21.

BERTAUX, D. (1979). Destinos pessoais e estrutura de classe: para uma crítica da antroponomia política. Rio de Janeiro: Zahar.

BULST, N. (2007). "Sobre o objeto e o método da prosopografia". Politeia: História e Sociedade, jan., vol 5, n⿳⺈ 1, p. 47-67.

BOURDIEU, P. (1996). Razões práticas: sobre a teoria da ação. Campinas: Papirus.

DURKHEIM, E. (2007). As regras do método sociológico. São Paulo: Martins Fontes. 
FAORO, R. (2001). Os donos do poder - Formação do patronato político brasileiro. Rio de Janeiro: Globo.

FREY, K. (2000). "Políticas públicas: um debate conceitual e reflexões referentes à prática da análise de políticas públicas no Brasil”. Planejamento e Políticas Públicas, jun., nº 21, p. 211-259.

HELlER, L.; CASTRO, J. E. (2007). "Política pública de saneamento: apontamentos teóricoconceituais”. Engenharia Sanitária e Ambiental, set., vol.12, nº 3, p.284-295.

HOCHMAN, G. (1998). A era do saneamento: as bases da política de saúde pública no Brasil. São Paulo: Hucitec/Anpocs.

MARQUES, E. C. (1999). "Redes sociais e instituições na construção do Estado e da sua permeabilidade”. Revista Brasileira de Ciências Sociais, out., vol. 14, nº 41, p. 45-67.

MATOS, H. (2009). Capital social e comunicação: interfaces e articulações. São Paulo: Summus.

OLIVEIRA, R.C. (2012). Na teia do nepotismo: sociologia política das relações de parentesco e poder político no Paraná e no Brasil. Curitiba: Insigth.

SANTOS, F. F. S. (2003). Capital social: vários conceitos, um só problema. 84 p. Dissertação de Mestrado em Administração Pública e Governo. Fundação Getúlio Vargas / Escola de Administração de Empresas de São Paulo.

SOUZA, C. (2003). "'Estado do campo' da pesquisa em políticas públicas no Brasil". Revista Brasileira de Ciências Sociais, fev., vol.18, no 51, p.15-20.

STONE, L. (2011). "Prosopografia". Revista de Sociologia e Política, jun., vol. 19, n 39, p. 115137.

http://site.sanepar.com.br/sites/site.sanepar.com.br/files/perfil_investidores_2012/estatuto_social_2 6032014.pdf; acesso em 05 de julho de 2015.

http://www.esmaelmorais.com.br/2015/04/ministerio-publico-confirma-farra-com-cargoscomissionados-na-sanepar/; acesso em 05 de julho de 2015.

http://www.gazetadopovo.com.br/vida-publica/mp-aponta-84-cargos-comissionados-ilegais-nasanepar-e-na-cohapar-c1e5dqpprnuz4qqufn2kgib3t; acesso em 05 de julho de 2015. 
http://www.planalto.gov.br/ccivil_03/_ato2007-2010/2007/lei/111445.htm, acesso em 30 de setembro de 2014. 